\title{
O que é a Grande História?
}

\author{
Distinguished Professor e diretor do Big History Institute \\ Macquarie University
}

Tradução de Daniel Barreiros

Correspondence | David Christian, david.christian@mq.edu.au

Citation | Christian, D. (2018) O que é a Grande História? Journal of Big History, II(3); 121 - 138.

DOI | http://dx.doi.org/10.22339/jbh.v2i3.2330

\section{RESUMO}

A grande história é um novo campo disciplinar acadêmico que estuda o passado em todas as suas possíveis escalas. Sua abordagem é histórica, mas reúne disciplinas da cosmologia à geologia, da biologia evolucionária à história humana. A partir de "O que é história?" de E.H. Carr, este ensaio descreve a evolução da grande história, e em particular, sua relação com a História como disciplina. Descreve em que consiste a nova disciplina e aquilo em que pode se tornar. Argumenta que a grande história pode ajudar a ultrapassar a fragmentação característica da educação e pesquisa modernas em todas as disciplinas. Fazendo-o, pode propor algo como uma narrativa de origens moderna e global, baseada na melhor produção científica moderna possível.

\begin{abstract}
Como erram aqueles que estudam mapas de regiões antes mesmo de terem aprendido precisamente a relação entre o Universo como um todo e suas partes, e a relação dessas partes entre si e delas com o conjunto, não estão menos enganados aqueles que pensam que podem entender histórias particulares antes que tenham ponderado sobre a ordem e a sequência da história universal e de todos os tempos, como se estivessem postas sobre uma mesa.
\end{abstract}

A Grande história representa uma tentativa naquilo que E. O. Wilson chamou de "consiliência", um retorno ao objetivo de se alcançar uma compreensão unificada da realidade, em lugar das visões fragmentadas que dominam a moderna educação e pesquisa acadêmica. ${ }^{2}$ Ainda que possa parecer algo novo, a consiliência como objetivo é algo antigo. E mesmo em seus formatos modernos, a grande história tem estado ao nosso redor por pelo menos um quarto de século. Assim, a publicação desse primeiro número do Journal of Big History oferece a oportunidade ideal para inventariarmos aquilo de que já dispomos sobre o assunto.

Esse artigo consiste de um relato pessoal sobre esse campo de estudo. Concebe a grande história como a forma moderna de um projeto antigo. Sou historiador de formação, de modo que meu relato põe foco na relação entre a grande história e a História como disciplina. Reflete a perspectiva de um historiador formado no mundo de língua inglesa, e destaca a relação entre a grande história e a pesquisa histórica anglófona. Mas não somente com essa pesquisa histórica anglófona, porque os debates que levanto tiveram suas contrapartes e ecos em muitas outras tradições de investigação histórica. Nem me disponho a focar somente a pesquisa histórica como é normalmente entendida no ambiente acadêmico, porque a grande história enxerga a história humana como parte de um passado muito mais amplo que inclui aquele passado estudado pelos biólogos, paleontólogos, geólogos e cosmólogos. Unindo diferentes perspectivas, escalas e diferentes disciplinas acadêmicas, todas tentando compreender as raízes mais profundas do mundo de hoje, a grande história pode transformar nosso entendimento do que é "história".

Entretanto, para captar a riqueza e o alcance desse vibrante novo campo de investigação, formação e ensino, nós precisaremos, em última instância, das perspectivas de macro-historiadores treinados em muitas outras disciplinas. Espero que esse ensaio possa encorajar esses estudiosos a oferecer suas perspectivas a respeito da história e da natureza da grande história. 


\section{A evolução dos estudos históricos no século XX}

Historiadores hão de reconhecer que o título desse artigo remete a um ensaio clássico, estudado pela maioria dos estudantes de história anglófonos. Foi escrito em 1961 por E. H. Carr, um historiador sovietólogo de origem inglesa. O livro de Carr surgiu a partir de uma série de palestras ministradas em Cambridge no ano de 1961, em honra de George Macaulay Trevelyan, um historiador que, diferentemente de Carr, via a história como disciplina literária e bastante distinta das ciências. Como historiador dedicado ao estudo da Rússia e da União Soviética, Carr levou a sério a insistência marxista de que a história deveria ser considerada um ramo da ciência, e essa ideia influenciou o meu próprio pensamento sobre a história uma vez que eu, também, me engajei no campo da história russa como estudante de pós-graduação no início da década de 1970.

Em O que é História?, Carr acompanha a evolução da disciplina histórica na Inglaterra no início do século XX. De certa forma, sua narrativa aponta para uma tendência sustentada de afastamento em relação a um realismo confiante, ao positivismo e mesmo ao universalismo de muitos pensadores históricos do século XIX, em direção a crescentes fragmentação e ceticismo. Começa citando a visão confiante de Lorde Acton acerca da investigação histórica ao final dos anos 1890, quando Acton esteve à frente da primeira edição da Cambridge Modern History. Acton via a Cambridge Modern History como uma "...oportunidade única de registrar...a plenitude do conhecimento que o século XIX está prestes a legar...". E ainda dizia: "Não teremos uma história definitiva nessa geração [mas]... toda informação está agora ao alcance, e todo problema encontra-se passível de solução." ${ }^{3}$ A visão de Acton a respeito da história é confiante, positivista e otimista, e assume que a história é parte de um projeto maior de expansão do conhecimento humano em geral. Sua visão de história é também ampla. Ele assume que historiadores deveriam almejar algum tipo de "história universal", muito embora ele pareça ter desejado se referir com essa frase não a uma espécie precoce de grande história, mas a algo mais próximo de uma "história mundial" ou "história global" moderna. Acton definiu a história universal como "aquela que difere da história combinada de todos os países." 4

No início do século XX, os estudos históricos na Inglaterra passaram por uma mudança profunda, e, na ocasião em que Carr escrevia, a disciplina estava mais fraturada e menos segura de si mesma. Essas mudanças eram parte de um movimento mais geral que afetava muitas disciplinas acadêmicas, das humanidades às ciências naturais, na medida em que a especialização e a profissionalização fragmentavam os estudos em compartimentos cada vez menores, cada um deles oferecendo sua própria e circunscrita visão de mundo. A especialização mostrou-se uma estratégia de pesquisa profunda, mas que só foi alcançada por meio da ruptura de laços ancestrais entre os campos do conhecimento, deixando-os progressivamente isolados uns dos outros. A noção de um mundo unitário de conhecimento, fosse amalgamado pelas cosmologias religiosas como a da cristandade, fosse pela prática científica - a visão por trás da tentativa de Alexander von Humboldt de escrever uma história científica universal em seu "Kosmos" - foi abandonada ${ }^{5}$. Nas disciplinas de humanidades, como a História, que careciam de algum tipo de paradigma unificador tal como o das ciências naturais na era de Darwin, de Maxwell e de Einstein, a especialização também solapou o confiante realismo epistemológico de Acton. ${ }^{6}$

Carr identifica algumas dessas mudanças ao citar a introdução da segunda edição da Cambridge Modern History, escrita por George Clark em 1957, mais de meio século após os pronunciamentos confiantes de Acton. Após citar as esperanças de Acton por uma "história definitiva", Clark escreve:

Historiadores de uma geração posterior não anseiam por tal prospecto. Eles esperam que seu trabalho seja sempre suplantado... 
A tarefa de exploração parece não ter fim, e alguns estudiosos impacientes se refugiam no ceticismo, ou, considerando que toda avaliação histórica envolve pessoas e pontos de vista, na doutrina que diz que tudo é tão bom quanto qualquer outra coisa, e que não há verdade histórica "objetiva."7

A perda de confiança em uma epistemologia realista ou naturalista em disciplinas como a História, aprofundou o hiato entre as "duas culturas", das ciências e das humanidades, algo que tanto aborrecia C. P. Snow em uma famosa palestra ministrada em $1959^{8}$. O hiato era particularmente amplo no mundo anglófono, porque o inglês, diferentemente de muitas outras línguas acadêmicas, limita o termo "ciência" às ciências naturais. Em inglês, a mera ideia de uma "ciência histórica" começou a parecer absurda. No tempo de Carr, os estudos históricos perderam confiança tanto em sua natureza "científica" quanto na epistemologia realista que ainda sustentava a pesquisa nas ciências naturais.

O ceticismo e a fragmentação intelectual minaram a antiga esperança de que a História fosse capaz de empoderar-nos, ajudando-nos a ter um melhor entendimento do presente, e abalaram a confiança no valor da pesquisa histórica. Enquanto se tornavam progressivamente mais isolados de outras disciplinas e mesmo uns dos outros, os historiadores esposaram visões cada vez mais fragmentadas acerca do passado, da natureza e dos objetivos da História. Esse sentido crescente de fragmentação foi a contraparte acadêmica do que Durkheim designou por anomia, a perda do senso de coerência e de significado, uma ideia que Carr descreve em uma nota de rodapé como "a condição de um indivíduo isolado da... sociedade" ${ }^{9}$. A anomia acadêmica surge do crescente isolamento dos estudiosos uns dos outros, e deles em relação a um mundo unificado de conhecimento. A única força que parcialmente mitigou o crescente senso de isolamento acadêmico foi o nacionalismo. Ainda que tribais pela sua própria natureza, as histórias nacionais, que florescem desde o século XIX, fornecem algum senso de coesão para historiadores trabalhando no âmbito de tradições historiográficas nacionais.

A posição pessoal de Carr situa-se entre o realismo científico robusto de Acton e o relativismo hesitante de Clark. Ele explora brilhantemente a complexa dialética entre a história como verdade, e a história como narrativas que contamos sobre o passado. Ele leva a verdade e a ciência a sério, porque acredita que a História, como a ciência, e como a verdade em geral, tem um propósito: o de nos empoderar. Ela nos empodera através da expansão de nosso entendimento do presente, e o faz através de plotar o presente no passado. "A função do historiador não é nem o amor ao passado nem sua emancipação pessoal em relação ao passado, mas dominá-lo e entendê-lo como chave para a compreensão do presente." 10 Por consequência, os mapas do passado criados pelos historiadores tinham de ser bons mapas. Como boa ciência, eles precisavam nos dar uma melhor noção do mundo real. Carr então, como Marx, era um realista filosófico, ao não enxergar qualquer distância fundamental entre as humanidades e as ciências naturais. "Cientistas, cientistas sociais, e historiadores estão engajados em diferentes ramos de um mesmo estudo: o estudo do homem e de seu ambiente, dos efeitos do homem sobre seu ambiente e de seu ambiente sobre o homem. O objetivo de estudo é o mesmo: aumentar o entendimento humano sobre o ambiente, e por sua vez, o seu domínio sobre ele."11

Por outro lado, Carr entendeu mais claramente que Acton que o passado não está lá simplesmente esperando para ser descoberto, "como um peixe na bandeja do peixeiro" ". AHistória consiste de narrativas construídas pelos historiadores sobre o passado, e o modo pelo qual construímos essas narrativas muda na medida em que nosso mundo e nossos propósitos se modificam. Precisamos de rigor empírico para nos aproximar da verdade acerca do passado, mas nesse processo de narrar sobre o passado, precisamos da habilidade dos contadores de histórias, incluindo o que Carr chamou de "entendimento imaginativo", a habilidade de compreender e ter empatia com aqueles que viveram no passado. ${ }^{13}$ Nesse sentido, Carr foi 
influenciado por um dos grandes filósofos ingleses da História, R. G. Collingwood, ainda que tenha alertado a respeito de sua ênfase no papel empático do historiador que, se levado muito longe, poderia resultar em extremo ceticismo ${ }^{14}$.

Particularmente influente no pensamento de Carr foi o equilíbrio dialético marxista entre ciência e ativismo. Marx insistiu na existência de um passado objetivo. Mas fazer algo a partir desse passado consiste em tarefa criativa, e a maneira pela qual nos aproximamos desse passado depende de quem somos, e do momento presente em particular, no qual escrevemos e estudamos. É essa a dialética que Marx descreve em uma famosa passagem de $O$ dezoito de Brumário de Luís Bonaparte:

Os homens fazem sua própria história, mas não a fazem da maneira que desejam; eles não a fazem em circunstâncias de sua própria escolha, mas em circunstâncias diretamente encontradas, dadas e transmitidas do passado. A tradição de todas as gerações mortas pesa como um pesadelo sobre as mentes dos vivos. ${ }^{15}$

Historiadores também "fazem sua própria história", mas o fazem "sob circunstâncias diretamente encontradas, dadas e transmitidas desde o passado". $\mathrm{O}$ que fazem a respeito do passado depende do tempo e do lugar em que escrevem. Mas as narrativas que constroem sobre o passado podem, por sua vez, influenciar aqueles passados que serão investigados por futuros historiadores. Na condição de ativista, Marx entendeu bem que o modo pelo qual descrevemos o passado pode moldar o futuro. Em verdade, ele desejou que seu próprio relato sobre a evolução do capitalismo tivesse um profundo impacto no futuro, tal como de fato veio a ocorrer.

Então, como Marx, Carr entendeu o complexo e delicado equilíbrio entre a história como verdade e a história como narrativa. A história é, segundo Carr, em uma passagem familiar a muitos estudantes de história, "um processo contínuo de interação entre o historiador e [os] fatos, um incessante diálogo entre o passado e o presente" ${ }^{16}$. Como a memória, a história, não invoca o passado, e sim, o recria.

Mas, que passado? Carr comprometeu-se ainda mais que Acton em ampliar o escopo da pesquisa histórica. Ele era, acima de tudo, um historiador russólogo, disposto a demonstrar a significância de histórias que foram negligenciadas por historiadores anglófonos. Admirador de Joseph Needham, insistiu também na importância da história chinesa, e das histórias de muitas partes do mundo para além da Europa.

Mas, ainda que o passado para Carr seja amplo, ele não é profundo. Demonstra pouco interesse na pré-história humana ou nas histórias da biosfera e do Universo. E isso talvez seja surpreendente, dado seu interesse em Marx, que via a história como parte de um contínuo de conhecimentos que incluía todas as ciências. Em verdade, Marx, como von Humboldt, foi um macro-historiador à frente de seu tempo. Mas Carr escreveu numa era de fragmentação acadêmica, e uma ideia de história universal não estava no seu radar, ou no radar de qualquer historiador anglófono de sua geração. Curiosamente, contudo, estava no radar de historiadores da União Soviética, país sobre cuja história Carr mais escreveu, porque a herança marxista da URSS assegurou que a ideia de história "universal" e "geral" nunca perdesse integralmente seu senso inclusivo. Essa é a razão pela qual, hoje, há uma florescente escola russa de pesquisa macrohistórica, liderada por acadêmicos como Andrey Korotayev e Leonid Grinin.

Em 2001, David Cannadine organizou uma coletânea de ensaios chamada $O$ que é História hoje? baseada em uma conferência em homenagem aos quarenta anos da obra de Carr ${ }^{17}$. Muito mudou desde que Carr escreveu. A disciplina histórica se tornou ainda mais fragmentada, tanto em conteúdo quanto em epistemologia, e muito menos segura de si. A visão universalista de Marx, de von Humboldt ou de H. G. Wells, parecia ter desaparecido por completo, 
sobrevivendo tão somente nas modalidades limitadas das histórias nacionais. Muita da mudança evidente na coletânea organizada por Cannadine reflete a proliferação de universidades, estudantes, historiadores e sub-disciplinas históricas do Pós-Guerra. Tratou-se de um fenômeno mundial, de modo que tendências similares podem ser encontradas, com variações, em muitas diferentes tradições historiográficas.

A coletânea de Cannadine não se referia mais a uma disciplina unificada, de modo que era apropriado que contasse com múltiplos autores. Mais historiadores e mais estudantes pareceram significar uma crescente diversidade de ideias a respeito de conteúdo, significado e propósito da pesquisa histórica. Cada capítulo se referia a um diferente tipo de história, de modo que nos aparecem com títulos como "O que é a História Social hoje?”, “O que é a História Intelectual hoje?”, “O que é a História Cultural hoje?”. A ausência de "O que é a História das mulheres hoje?" e "O que é a História ambiental hoje?" é marcante, ainda que Cannadine insista que seu livro reflete tão somente uma pequena fração das subdisciplinas nas quais a História hoje está dividida.

A fragmentação foi acompanhada por crescente ceticismo acerca da objetividade e da natureza científica da disciplina. De fato, a maioria dos historiadores continuou a abordar os detalhes de suas pesquisas com um empirismo robusto e realista, a ponto de muitos terem caricaturizado a disciplina como nada mais que um catálogo de fatos. Mas, ao passo que o círculo de perguntas se ampliou, a confiança dos historiadores pareceu murchar, e poucos seguiram confortáveis com a ideia de estudos históricos como parte de um sistema maior de conhecimento e significado. Historiadores se tornaram cada vez mais isolados de outras disciplinas (o declínio da história econômica é um exemplo impactante desse processo), e mesmo uns dos outros, e qualquer consenso acerca da natureza e objetivos da História parecia ter evaporado. Em um ensaio introdutório, Richard Evans destacou o crescente foco na era pós-moderna no papel subjetivo e criativo do historiador, e em seu lugar como contador de histórias.
Essa abordagem foi sintetizada pela obra clássica de Hayden White, de 1973, Meta-história: a imaginação histórica na Europa do Século XIX, focada quase que integralmente nos aspectos literários da produção historiográfica, em vez de na verdade reclamada por essa produção. A produção historiográfica parecia ter se fragmentado em múltiplas e incomensuráveis narrativas sobre o passado, cada qual representando uma perspectiva particular, e nenhuma delas confiante em suas alegações de portadoras de verdade histórica. Historiadores pareceram tomados de um profundo ceticismo em relação às grandes narrativas ou metanarrativas, postura que Jean-François Lyotard viu como elemento definidor do pensamento pósmoderno. ${ }^{18}$

Ainda, não obstante os tremores parcamente registrados no sismógrafo da coletânea de Cannadine, por volta do ano 2000, a ideia a respeito de uma nova forma de história universal já ecoava nas margens da pesquisa historiográfica. A História Mundial florescia nos Estados Unidos, contava com uma bem fundada organização acadêmica e um periódico bem sucedido (The Journal of World History), e era ensinada em um crescente número de universidades e escolas. Mas vários acadêmicos àquela altura já se aventuravam em ir além da História Mundial. Começavam a explorar a possibilidade de uma genuína história universal que incorporasse todo o passado, incluindo os passados da biosfera e de todo o Universo. Por volta do ano de 2001, eu já ensinava grande história havia doze anos, mas eu era apenas um componente de uma pequena, porém vigorosa, comunidade de acadêmicos movendo-se na mesma direção. Eric Chaisson já ensinava versões da grande história para astrônomos por mais de vinte anos, e grande história era ensinada em Amsterdã por Fred Spier e Joop Gouldsblom, em Dallas por John Mears, em San Rafael por Cynthia Stokes Brown, em Melbourne por Tom Griffiths e Graeme Davidson, entre outras partes do mundo. A grande história infiltrou-se numa disciplina que olhava numa direção oposta. 
Hoje, quinze anos após a coletânea organizada por Cannadine, a grande história segue sendo marginal, mas começa a chacoalhar a disciplina historiográfica. ${ }^{19}$ E.merge uma literatura que prova que a grande história pode ser escrita com rigor e precisão, e pode trazer insights novos e transformadores sobre o passado. ${ }^{20}$ Grande história vem sendo ensinada com sucesso em várias universidades, na maior parte em países anglófonos, e mesmo aqueles departamentos de História que não oferecem cursos nessa abordagem, frequentemente incluem discussões macro-históricas em seus seminários. Existem vários MOOCs (Massive Open Online Courses) sobre a grande história. Conta com uma associação acadêmica (a IBHA), que já realizou três grandes conferências, e agora, com uma revista. A Macquarie University fundou o Big History Institute, que organizou duas conferências de pesquisa. Grande história tem sido ainda ensinada em centenas de escolas secundárias, principalmente nos Estados Unidos e na Austrália, por meio do "Big History Project", um curso gratuito e online, lançado em 2011 e financiado por Bill Gates.

O que parecia há apenas algumas décadas uma abordagem historiográfica arcaica, irrealista e perversa começa a parecer uma forma poderosa, rigorosa e mesmo transformadora de pesquisa moderna, que pode reconectar o ensino e a pesquisa historiográfica mais uma vez com outras disciplinas tanto no campo das humanidades quanto das ciências.

\section{Por que o retorno a uma História Universal? O que aconteceu?}

Algumas das mudanças cruciais aconteceram no âmbito da própria disciplina histórica. Sempre houve uns poucos estudiosos, como H. G. Wells ou Arnold Toynbee, que mantiveram viva a visão de um entendimento mais amplo do passado. Mas a pesquisa especializada também lançou base para uma compreensão mais extensa do passado, por meio da geração de um volume colossal de produção nova, abordando assuntos, regiões e épocas ignorados por uma geração anterior de historiadores. Felipe
Fernandez-Armesto, um historiador mundial com interessantes extraordinariamente amplos, referiu-se a isso em um capítulo na citada coletânea de Cannadine:

"historiadores escavam cada vez mais profundamente, em sulcos cada vez mais estreitos, e em solo cada vez mais ressecado, até que os sulcos colapsam e eles são enterrados sob sua própria aridez. Entretanto, por outro lado, sempre que alguém consegue achar seu caminho para a superfície, há tanto mais daquele campo para investigar, tanto trabalho novo e enriquecedor, que pode mudar perspectivas ou ampliar estruturas de comparação."21

Mas muitas das mudanças que permitiram um retorno da História Universal ocorreram para além da disciplina histórica, e particularmente, no campo das ciências naturais, que sempre foram mais amistosas em relação à ideia de consiliência do que foram as humanidades ${ }^{22}$. O físico quântico Erwin Schrodinger já havia antecipado novas formas de unificação acadêmica em um livro escrito ao fim da Segunda Grande Guerra, sobre a natureza da vida:

Herdamos de nossos antepassados o anseio vívido por um conhecimento unificado e abarcante. O próprio nome dado às instituições dedicadas ao mais alto aprendizado nos lembra de que, desde a Antiguidade a ao longo de muitos séculos, a dimensão universal foi a única a receber crédito integral...Sentimos claramente que só agora começamos a reunir material confiável para amalgamar a soma total do que é conhecido."23

Nas ciências naturais, como nas humanidades, estudos especializados produziram, por muitas décadas, uma vasta safra de novas informações e ideias. Igualmente importante foi a emergência de ideias acerca de um paradigma novo e unificador. As mais importantes entre elas são a cosmologia do Big Bang, a tectônica de placas e a síntese moderna darwiniana. 
Os novos paradigmas estavam parcamente visíveis enquanto Carr escreveu. O ADN foi descoberto na própria instituição que abrigava Carr, a Universidade de Cambridge, em 1953, mas o significado completo da descoberta só se tornaria evidente uma ou duas décadas depois. As descobertas que consolidariam o tectonismo de placas e a cosmologia do Big Bang ainda estariam alguns anos à frente. Por volta de 1970, contudo, os novos paradigmas já eram capazes de encorajar esperanças de uma unificação do conhecimento, pelo menos nas ciências naturais. Alguns cientistas começavam a falar de "Grandes Teorias Unificadas".

Particularmente impactante é o fato de que os novos paradigmas científicos eram históricos em sua natureza. Foi-se o universo estático de Newton, substituído por um universo que operava de acordo com leis históricas e evolucionárias. E. H. Carr estava consciente acerca de uma "virada histórica" nas ciências naturais e de sua significância para a História, ainda que seus insights viessem a ser ignorados pela maior parte dos historiadores pelos cinquenta anos seguintes, ou quase. A ciência, escreveu Carr:

passou por uma profunda revolução...O que Lyell fez pela geologia e Darwin pela biologia foi agora feito pela astronomia, que se torna uma ciência a respeito de como o Universo se tornou o que ele é...O historiador tem alguma desculpa em sentirse mais em casa no mundo da ciência de hoje do que poderia sentir-se há cem anos. ${ }^{24}$

No mundo anglo-saxão, a cosmologia do Big Bang encorajou astrônomos com Carl Sagan a recontar a história do Universo, enquanto o tectonismo de placas encorajou geólogos como Preston Cloud a escrever novas histórias sobre o planeta Terra. ${ }^{25} \mathrm{O}$ fato era que muitos cientistas naturais estavam diante do mesmo trabalho confuso que os historiadores - tentando reconstruir um passado desaparecido a partir de pistas aleatórias que esse passado legou ao presente. A virada histórica nas ciências naturais trouxe os métodos dos cientistas para mais próximo do método dos historiadores. Experimentos controlados sobre a origem da vida na Terra ou sobre a Revolução Russa estavam fora de questão. Em vez disso, descobriu-se que muitas disciplinas científicas deparavam-se com o mesmo desafio metodológico que os historiadores: o de coletar o maior número de pistas do passado que pudessem - desde luzes estrelares antiquíssimas, a cristais de zircão e trilobitas fósseis - e usá-las para reconstruir um relato plausível e significativo do passado. Esse era um território familiar para os historiadores. Evidências falsificacionistas definitivas, defendidas por Karl Popper, raramente estavam disponíveis, e outras competências mais difusas, tais como o reconhecimento de padrões ou sugestões baseadas numa prolongada familiaridade com determinado campo de estudo, adquirem relevância crescente nas ciências naturais tanto quanto nas humanidades. ${ }^{26}$

Particularmente importante para a emergência das formas modernas de história universal foi $\mathrm{o}$ desenvolvimento das técnicas de datação radiométrica capazes de prover um firme arcabouço cronológico para narrativas a respeito de um passado profundo. ${ }^{27}$ Quando H. G. Wells tentou a elaboração de uma história universal logo após a Primeira Grande Guerra, as partes dessa narrativa que se referiam a um passado mais remoto ficaram frouxas porque, como Wells admitiu, toda a sua datação absoluta requeria registros escritos, e ele não podia oferecer qualquer desses para qualquer tempo anterior à Primeira Olimpíada (776 a.C). ${ }^{28}$ Geólogos do século XIX aprenderam como reconstruir cronologias relativas através do estudo da deposição de rochas antigas, mas nenhum deles era capaz de dizer quando a explosão cambriana ocorreu nem quando a Terra se formou.

Tudo isso mudou com a emergência das técnicas de datação radiométrica nos anos 1950. Em 1953, Claire Paterson utilizou a meia-vida do urânio em meteoritos para determinar que a Terra tinha 4,56 bilhões de 
anos. Essa datação mantém-se até hoje. Quando Carr escreveu em 1961, a datação radiométrica estava apenas começando a transformar o pensamento de arqueólogos e pré-historiadores. Em 1962, na gruta de Kenniff em South Queensland, John Mulvaney usou técnicas radiométricas para demonstrar que humanos viveram na Austrália desde antes do fim da última era glacial, e em algumas décadas seguintes, as datas mais antigas para a colonização humana na Austrália seriam recuadas ainda mais, para entre cinquenta mil ou talvez sessenta mil anos atrás. ${ }^{29}$ Como Colin Renfrew escreveu:

..o desenvolvimento de métodos de datação radiométrica...permitiu a construção de uma cronologia para a pré-história em todas as partes do mundo. Ela foi, aliás, uma cronologia livre de quaisquer suposições a respeito de relações ou de desenvolvimentos culturais, e que poderia ser aplicada tanto a sociedades ágrafas como àquelas que dispunham de registros escritos. Ser préhistórico não significava mais ser ahistórico em um sentido cronológico. ${ }^{30}$

A seu tempo, técnicas radiométricas e outras formas de datação tornaram possível construir cronologias rigorosas remontando às origens do Universo. Pela primeira vez, era possível contar a história universal baseada em uma cronologia robusta.

Algumas dessas mudanças acabaram por ser registradas na coletânea de ensaios organizada por David Cannadine. Em seu último capítulo, Felipe Fernandez-Armesto argumenta que a História ampliou seu escopo, especialização após especialização, e agora precisa abraçar as ciências naturais: "a História não pode mais permanecer encampada em uma das 'duas culturas'. Seres humanos são obviamente parte do continuum animal" ${ }^{31}$. Em 1998, o grande historiador mundial William H. McNeill argumentou que os historiadores precisam engastar a história da humanidade em uma história da biosfera e mesmo do Universo como um todo:
Seres humanos, ao que parece, pertencem ao Universo e compartilham de seu caráter instável e evolutivo... O que ocorre entre seres humanos e o que acontece entre as estrelas parece ser parte de uma narrativa grande e evolutiva, que caracteriza a espontânea emergência da complexidade que gera novas formas de comportamento a cada nível de organização, dos quarks e leptons mais minúsculos às galáxias, das longas cadeias de carbono aos organismos vivos e à biosfera, e da biosfera aos universos simbólicos do significado sob os quais os seres humanos vivem e labutam. ${ }^{32}$

Em seus últimos anos, McNeill tornou-se crescentemente interessado na ideia de uma grande história, vendo-a como uma extensão natural de sua própria visão ampliada da História. É como seu filho, John, escreveu: "era a coisa que mais lhe entusiasmava (além dos netos)." 33

\section{O que é a Grande História?}

\section{Então, o que é a grande história?}

$\mathrm{Na}$ parte final desse ensaio, eu gostaria de explorar várias descrições sobrepostas do que a é grande história e do que ela poderia ser. Essas são reflexões pessoais, e algumas delas são especulativas. Mas eu espero que possam interessar mesmo aqueles que são menos persuadidos por elas do que eu propriamente sou. E torço ainda para que possa encorajar uma discussão mais ampliada sobre a grande história e sobre seu futuro. Meus pensamentos estão organizados, de forma lassa, em um espectro que vai do polo "verdade" na dialética da história de Carr ao polo "contação de histórias".

O objetivo da grande história, tal como o de todo bom conhecimento, é nos empoderar por meio de ajudar no entendimento a respeito do mundo em que vivemos. A grande história nos empodera ajudando em um melhor entendimento do mundo em que vivermos. Como toda forma de História, a grande história empodera-nos primeiramente ao plotar o presente no passado, de modo a nos auxiliar em um 
melhor entendimento a respeito de como o mundo de hoje se tornou o que ele é. Essa afirmação a respeito do propósito da história assume um entendimento realista ou naturalista do conhecimento. Como criaturas evoluídas, interagimos com o ambiente com algum grau de sucesso, e esse sucesso pressupõe que nós (como organismos vivos) somos capazes de obter um conhecimento real, ainda que limitado, desse mesmo ambiente. Ainda que conscientes a respeito dos limites desse conhecimento, a grande história, como a ciência em geral, resiste às formas extremas de ceticismo e de relativismo. Constrói-se sobre as mesmas bases realista e naturalista da boa ciência, e tem o seu mesmo objetivo final, que é o empoderamento.

A grande história é universal. Mas, se o entendimento do passado pode nos empoderar, não deveríamos tentar compreender todo o passado? O que distingue a grande história mais decisivamente em relação a outras formas de estudo histórico é sua tentativa de compreender o passado como um todo. Aspira ao entendimento universal da história. A grande história não é hostil ao estudo histórico especializado. Pelo contrário, ela é totalmente dependente do rico manancial da pesquisa especializada. Mas ela tenta reunir as descobertas provenientes da pesquisa especializada em uma ampla visão unificadora, da mesma forma que milhões de mapas locais se conectam para formar um único mapa mundi. Esses objetivos ambiciosos significam que a grande história nada contra a corrente da fragmentação intelectual que estruturou muito da pesquisa no século XX. A grande história objetiva a consiliência, naquilo que Alexander von Humboldt uma vez chamou de "Louco frenesi... de representar num único trabalho todo o mundo material." 34

Muitas consequências interessantes fluem da ambição universalista da grande história. Ela não reconhece barreiras disciplinares ao conhecimento histórico. Presume a existência de uma vasta gama de disciplinas historicamente orientadas, todas elas vinculadas entre si pelo mesmo projeto: o de reconstituir como nosso mundo se tornou o que ele é.
De fato, fico imaginando se não seremos capazes um dia de ver um rearranjo dos campi universitários, de modo que, ao invés de estarem localizadas as ciências em um lado, e noutro as humanidades, se possa encontrar uma zona dedicada às "ciências históricas", na qual estejam astrônomos, geólogos, biólogos evolucionários, neurocientistas e historiadores, todos trabalhando juntos.

Essas aspirações universais da grande história significam que ela irá acolher todas as áreas do conhecimento que tenham produzido relatos sobre o passado que sejam rigorosos e baseados em evidência, e toda disciplina cujos insights possam iluminar o passado. Isso significa que, no momento, faz sentido traçar um limite entre tudo que ocorreu exatamente após o Big Bang - um passado que pode ser reconstruído com evidência aos borbotões - e tudo que precede o Big Bang, território sobre o qual há bastante especulação interessante, mas não, até o momento, uma narrativa firme e fundada em evidência. Isso pode mudar, é claro, e sendo o caso, a própria narrativa macro-histórica irá se expandir para incorporar, talvez, evidência em favor de um multiverso ou da teoria das cordas. Mudanças similares podem ocorrer em outras partes da narrativa macro-histórica, à medida que biólogos prospectam a origem da vida na Terra, ou astrônomos procuram por vida em outros sistemas estelares, ou à medida que neurocientistas e psicólogos começarem a compreender o difícil problema representado pela consciência, ou historiadores obtiverem um melhor entendimento do papel da religião e da ciência na história humana em múltiplas escalas.

Com essas qualificações, a grande história almeja um entendimento compreensivo da história, o que seria o equivalente intelectual de um mapa mundi do passado. Como tal, a grande história pode ajudarnos a ver não apenas as maiores nações e os oceanos do passado, mas também os vínculos e sinergias que conectam diferentes "continentes acadêmicos", regiões e ilhas em um único mundo de conhecimento. Sua perspectiva ampla também encoraja-nos ao movimento por entre múltiplas escalas, aquelas do 
Universo em si, dos humanos, das células individuais, nas quais milhões de reações precisamente calibradas ocorrem a cada segundo. A grande história encorajanos a ligar os pontos no tempo e no espaço, a olhar para as sinergias que vinculam entidades díspares, disciplinas e escalas. Acadêmicos russos como Andrey Korotayev têm sido particularmente ativos na importante tarefa de procurar por padrões matemáticos na evolução da complexidade em múltiplas escalas.

Focando as redes de ideias que vinculam as disciplinas, a grande história pode nos ajudar a superar as formas mais extremas de ceticismo características de grande parte da pesquisa acadêmica do século XX, particularmente nas humanidades. Nas mãos de Durkheim, a ideia de anomia referia-se à falta de um sentido claro de lugar ou de significado, uma condição de desabrigo intelectual na qual o próprio mundo tem pouco sentido e os indivíduos começam a se sentir isolados a ponto de contemplar o suicídio. A extrema fragmentação da pesquisa acadêmica do século XX permitiu um grande progresso intelectual, disciplina a disciplina. Mas o fez ao custo de isolar as disciplinas umas das outras, o que limitou as possibilidades para uma visão ampla e unificada, e para mecanismos de verificação de verdade entre as disciplinas. Particularmente nas humanidades, o isolamento intelectual gerou formas acadêmicas de anomia que minaram a confiança em quaisquer alegações acerca da capacidade de geração de significado ou de uma compreensão mais geral da realidade. O ceticismo pós-moderno compartilhado por tantos estudiosos nas humanidades ao final do século XX foi um corretivo útil para formas superconfiantes de positivismo. Mas, quando levado aos extremos, criou um senso fragmentado de realidade que pode ser profundamente desempoderador, intelectual e eticamente. Alguns o viram como o equivalente acadêmico ao suicídio.

A grande história retorna, com a devida modéstia científica, ao antigo projeto de tentar montar mapas unificados da realidade. Quebrando as partições entre disciplinas, a grande história pode ajudar a re-estabelecer uma relação mais equilibrada entre os estudos especializados e ideias amplas e paradigmáticas.

\section{A grande história é colaborativa e coletiva. A} narrativa macro-histórica é montada como um vasto mosaico, usando peças de muitos diferentes países, épocas e disciplinas acadêmicas. Todo estudo é colaborativo. Mas o extraordinário alcance da grande história coloca a colaboração no coração da nova disciplina. Uma narrativa macro-histórica rica e confiável não será o produto de mentes acadêmicas individuais, mas a criação conjunta de milhões de mentes.

A colaboração acadêmica extrema, necessária para se escrever a grande história, deve encorajar o repensar acerca daquilo que entendemos por expertise. A especialização encorajou a noção de que, se você afunila o horizonte de indagações o suficiente, acadêmicos individuais podem alcançar a maestria em um campo. Eles se tornam experts. Essa visão foi sempre ingênua porque os experts mais verticalizados em seu estudo se apropriarão de insights e de paradigmas vindos de fora de seu campo de expertise. Mas a extraordinária amplitude da grande história significa que, muito embora ela vá se construir a partir dos insights de experts, ela irá também requerer muitas outras habilidades acadêmicas, nem todas valorizadas nesse mundo atual de conhecimento fragmentado. A grande história requer, acima de tudo, uma habilidade em compreender e então conectar a produção de muitos acadêmicos de diferentes disciplinas. Ela demanda amplitude tanto quanto profundidade, bem como um olhar aguçado para sinergias inesperadas entre disciplinas. E requer ainda a habilidade de sintonizar as diferentes frequências intelectuais de múltiplas disciplinas. Macro-historiadores precisarão ser tradutores interdisciplinares, sensíveis às súbitas nuances na forma pela qual diferentes disciplinas se utilizam de conceitos similares, termos e métodos. E ainda farão perguntas interdisciplinares profundas. Existem ideias que funcionam bem transversalmente 
a muitas disciplinas, da cosmologia à biologia e à história, ideias como as de "regimes" e de "Goldilocks conditions" ${ }^{35}$ descritas por Fred Spier, ou as taxas de "densidade de energia livre" que estão no centro do trabalho de Eric Chaisson? Pode a ideia de entropia, que representa um poderoso papel da física, iluminar nosso entendimento da história humana? Pode o maquinário molecular em nível atômico explorado hoje em dia por nanobiólogos sugerir novas formas de gerenciar fluxos de energia no mundo atual? ${ }^{36}$. Existem mecanismos universais (talvez alguma forma de darwinismo universal) que explique o aparecimento de entidades progressivamente complexas a despeito da segunda lei da termodinâmica?

Ao focar não apenas as ilhas individuais $\mathrm{e}$ continentes dos estudos modernos, mas também as muitas ligações entre eles, a grande história pode prover um novo tipo de arcabouço para a investigação e o pensamento interdisciplinares. Pesquisadores familiarizados com o mapa mundi do passado próprio da grande história irão naturalmente buscar ideias e métodos úteis para além das disciplinas nas quais são especialistas. Pesquisa transdisciplinar tornarse-á particularmente importante à medida que mais e mais problemas, da mudança climática ao estudo do câncer ou das crises financeiras, comecem a depender dos achados e insights provenientes de múltiplas disciplinas. Em verdade, o próprio sucesso da pesquisa no âmbito das disciplinas explica porque cada vez mais e mais problemas importantes e interessantes agora repousam no espaço entre as disciplinas. Ao passo que a pesquisa interdisciplinar se torna mais e mais importante, a grande história pode oferecer um novo modelo de expertise acadêmica, que demanda amplitude do conhecimento e atenção para sinergias interdisciplinares inesperadas.

A jovem disciplina da grande história tem também mostrado que a colaboração intelectual é uma característica distinta de nossa espécie, Homo sapiens. Ainda que muitos traços evolucionários nos definam como uma espécie, nossa criatividade tecnológica parece ter sido consolidada pela evolução de uma forma particularmente poderosa de linguagem, que nos permite trocar ideias e insights com tal precisão e volume que começam a se acumular na memória coletiva. Não sabemos de qualquer outra espécie em que o conhecimento aprendido se acumula através de múltiplas gerações de modo que gerações posteriores conheçam não somente coisas diferentes, mas mais coisas que a geração passada. E essa diferença tem se mostrado transformadora. A acumulação de informação aprendida por milhões de indivíduos através de múltiplas gerações explica nosso crescente controle sobre recursos e fluxos de energia na biosfera. Essa tendência acelerada moldou muito da história humana, e culmina hoje em nos tornar a mais poderosa força de mudança na biosfera. Em meus trabalhos, descrevi essa capacidade de compartilhar e acumular informação como "aprendizado coletivo". Deu a nós, humanos, não apenas um crescente controle sobre os fluxos de energia e recursos no meio ambiente, mas também um progressivo insight acerca do mundo e do Universo em que habitamos. A ciência moderna, tal como as modernas religiões e literaturas, são criações de milhões de indivíduos, trabalhando no âmbito de redes compartilhadas de conhecimento. Em apenas um século, a esfera da mente humana, ou a noosfera, como designou Vernadsky, tornou-se uma força de mudança planetária. ${ }^{37}$

Minha convicção pessoal está em que a ideia de "aprendizado coletivo" nos oferece um paradigma que pode estruturar nosso entendimento da história humana e da natureza distinta de nossa espécie. A história humana é movida pelo aprendizado coletivo da mesma maneira que a história dos organismos vivos é movida pela seleção natural. Se essa ideia for amplamente correta, ela ilustra a capacidade da grande história em esclarecer problemas profundos através de nos ajudar a vê-los contra um pano de fundo excepcionalmente amplo, como parte de um mapa mundi do conhecimento moderno.

A Grande história é uma narrativa. Até aqui discuti a natureza da verdade que pode ser reclamada pela grande história, e sua capacidade de sinergizar 
pesquisas interdisciplinares e colaborativas. Mas, é claro, a grande história também conta uma estória. Ela emerge, como Carr escreveu a respeito de toda história, a partir de um "infindável diálogo entre presente e passado". Seus dois polos são o passado como um todo, e os historiadores que observam esse passado a partir de uma posição privilegiada no presente. Como a história em geral, a grande história é de fato o produto de historiadores que constroem a narrativa macro-histórica. Isso quer dizer, é claro, que a grande história está evoluindo e irá evoluir, como todas as narrativas, à medida que for contada por diferentes narradores, escrita em diferentes contextos, e com diferentes preocupações.

A grande história é uma narrativa de origens. Mas devido às suas ambições universalistas, ela não é somente apenas uma estória qualquer acerca do passado. Suas ambições universais significam que ela compartilha muito com as narrativas de origens tradicionais. Até onde sabemos, todas as comunidades humanas tentaram construir relatos unificados a respeito da origem do todo que nos rodeia. É nesse sentido que emprego a ideia de "narrativas de origens". Elas tentam consolidar e passar adiante tudo o que é conhecido em uma dada comunidade a respeito de como nosso mundo se tornou o que é. Elas são extraordinariamente poderosas se forem acreditadas, se soarem como verdadeiras àqueles que as ouvem e as recontam, independentemente de tratarmos de comunidades de coletores do mundo paleolítico, ou de grandes tradições filosóficas e religiosas das maiores civilizações mundiais, do confucionismo ao budismo, até as tradições do mundo asteca, da cristandade e do islã. São também poderosas porque compartilhadas pele maioria dos membros de uma dada comunidade, que aprendem os rudimentos de suas narrativas de origens enquanto crianças, e então internalizam essas estórias ao longo de muitos anos de educação, com crescente detalhe e sofisticação. Até onde sabemos, narrativas de origem são encontradas no núcleo de todas as formas de educação. Elas proveram conhecimento fundacional em seminários e universidades, e também nas ricas tradições orais passadas pelos anciãos em todas as comunidades de caçadores-coletores.

À luz dessa discussão é evidente que a noção de anomia durkheimiana também pode ser entendida como o estado mental daqueles que carecem de acesso a narrativas de origens críveis, ricas e acreditadas. Anomia intelectual é um estado de desmapeamento e de falta de significado. Curiosamente, esse é o estado intelectual que se torna a norma no século $\mathrm{XX}$, ao passo que a globalização e a ciência moderna golpearam a confiança nas narrativas de origem tradicionais, tanto nos centros metropolitanos do mundo quanto em suas margens coloniais. Em toda parte, sistemas educacionais modernos e seculares não mais ensinavam no âmbito de tradições compartilhadas de conhecimento fundacional.

Alguns viram no declínio das narrativas de origem tradicionais algo emocionante e libertador, e sacramentado nas múltiplas e livremente flutuantes perspectivas de um mundo sem uma narrativa originária compartilhada. Mas muitos, tanto no mundo colonial quanto nas pátrias metropolitanas, experienciaram, e continuam a experienciar, um profundo sentimento de perda. Hoje, nos acostumamos tanto a um mundo sem ideias estruturantes universais (particularmente nas humanidades) que se torna fácil esquecer o quão doloroso foi a perda do senso de coerência intelectual que acompanhava a confiança em uma narrativa de origens. Mas esse sentimento de perda é evidente em muito da literatura, filosofia e arte do fim do século XIX e início do século XX.

Aqui vão apenas dois exemplos mais ou menos fortuitos do que quero dizer. Em seu poema de 1851, "Dover Beach", Matthew Arnold escreve:

O mar da fé

Esteve um dia também no pleno e curvo litoral da Terra

Repousava como as dobras de um brilhante cinto engelhado.

Mas agora só ouço

Seu melancólico, longo e retraído rugido, 
Retirando-se ao sabor

Do vento da noite, para as vastas bordas sombrias

E praias desoladas do mundo.

O poema continua com uma visão terrível de um futuro sem coerência e significado:

Ah, amor, sejamos francos

Um com o outro! Porque o mundo, que parece

Estar diante de nós como uma terra de sonhos,

Tão variado, tão belo, tão novo,

Em verdade não tem nem júbilo, nem amor, nem luz,

Nem certeza, nem paz, nem alívio para a dor;

E aqui estamos como em uma planície sombria

Varrida por alarmas confusos de luta e fuga,

Onde exércitos ignorantes se confrontam na noite.

"The Second Coming" de W. B. Yeats, escrito em 1919, logo após a Grande Guerra, pareceu concretizar a visão apavorante de Arnold sobre o futuro.

Girando e girando no volteio crescente

O falcão não pode ouvir o falcoeiro

As coisas desmoronam; o centro não se mantém;

Mera anarquia desenfreada sobre o mundo,

A maré sangrenta incontrolada, e em toda parte

A cerimônia da inocência é afogada;

O poema se encerra com uma famosa e atemorizante imagem:

Qual tosca besta, chega enfim sua hora,

Rasteja-te a Belém para nascer?

Aespecialização, e a perdadasnarrativas unificadoras tradicionais, foram sintomáticas de um mundo caótico e incoerente descrito em muito da literatura, da arte e da filosofia do século XX. Em verdade, frequentemente se assume que esse mundo de disciplinas e perspectivas isoladas e mesmo incomensuráveis é característico da modernidade em geral. $\mathrm{O}$ mundo moderno reuniu com tal violência povos, culturas, religiões e tradições que produziu um sentido crescente de humanidade enquanto unidade, enquanto simultaneamente minava a confiança nas visões unificadoras tradicionais do mundo. Em $O$ Manifesto Comunista, lemos que na era burguesa da história humana: "Todas as relações fixas e cristalizadas, com seu cortejo de arcaicos e veneráveis preconceitos e opiniões, são varridas, todas aquelas recém-formadas se tornam antiquadas antes mesmo que possam se ossificar. Tudo que é sólido desmancha no ar, tudo que é sagrado é profanado...". Num livro sobre a modernidade que toma seu título dessa passagem, Marshall Berman afirma que o mundo moderno criou "uma unidade paradoxal, uma unidade de desunião; ele nos lança em um redemoinho de perpétua desintegração e renovação, de peleja e contradição, de ambiguidade e angústia. Ser moderno é fazer parte de um universo no qual, como Marx disse: 'tudo que é sólido desmancha no ar'."38

Mas uma interpretação diferente também é possível. Talvez ao longo de boa parte do século XX, tenhamos vivido em um tipo de canteiro de obras intelectual, rodeado pelos escombros de velhas narrativas de origens, enquanto uma nova narrativa originária era construída ao nosso redor, uma história para a humanidade como um todo. A melhor evidência para essa ideia é a re-emergência das narrativas unificadoras nos últimos cinquenta anos. Visto dessa perspectiva, a grande história é o projeto que almeja obter e construir uma moderna e global narrativa originária.

A grande história é uma narrativa de origens para o Antropoceno. Quem sabe, então, possamos pensar na grande história como a narrativa originária para o estranho mundo do século XXI. A grande história se funda nas conquistas intelectuais da ciência moderna do século XX, mas também é ela produto de um mundo globalizado, que é radicalmente diferente daquele em que viveu E. H. Carr. O conhecimento científico avançou mais rápido que poderíamos imaginar, e 
novas tecnologias como a Internet criaram um mundo muito mais entrelaçado. Mas talvez as mudanças mais importantes surjam dessa grande aceleração, desse espantoso crescimento da demografia humana, do uso de energia e do controle sobre o meio ambiente, e da interconexão entre os seres humanos, nesses sessenta anos desde que Carr escreveu. Nesse breve período, nós humanos tornamo-nos, coletivamente, a força mais importante de mudança na biosfera, a primeira e única espécie a cumprir esse papel nos quatro bilhões de anos de vida na Terra. Esse é um desdobramento que Carr não poderia ter imaginado em 1961. Essa mudança espetacular significa que perguntas a respeito da natureza e da fonte do assombroso poder exercido coletivamente por sete bilhões e quatrocentos mil humanos têm um alcance muito maior do que tinham no tempo de Carr. Nesse sentido, a grande história pode ser pensada como uma narrativa originária para a Época Antropocênica na história humana.

Necessitamos da escala ampla da grande história para vermos o Antropoceno de modo claro, dado que ele não se configura apenas como um ponto de virada na moderna história mundial, mas como uma fronteira significativa na história humana em geral, e mesmo na história do planeta Terra. A maior parte dos estudos históricos contemporâneos se debruça sobre os últimos quinhentos anos. O perigo dessa perspectiva encurtada está em normalizar a história recente, fazendo das econômica e socialmente dinâmicas sociedades dos séculos recentes algo típico na história humana em geral. Elas não o são. Seu dinamismo é extraordinário e excepcional. A própria ideia de história, de mudança em longo prazo, é moderna e, como John McNeill mostrou, a escala da transformação na era moderna, e particularmente desde meados do século XX, é de fato "algo novo sob o sol." ${ }^{39}$ Em contraste, a maior parte das pessoas na maior parte das sociedades ao longo dos últimos duzentos mil anos viveram suas vidas em estruturas e ambientes que pareciam relativamente estáveis, porque a mudança era tão lenta que não podia ser observada na escala de umas poucas gerações.

Somente no âmbito das vastas escalas da grande história se torna possível ver com clareza que a
Época Antropocênica é estranha não apenas na escala humana, mas também naquela da história do planeta Terra. Talvez por essa razão, em um artigo recente, um grupo de paleontólogos sugeriu que o Antropoceno representa uma das três mais importantes mudanças na história da biosfera, juntamente com o surgimento da vida, quase quatro bilhões de anos atrás, e da vida multicelular há seiscentos milhões de anos ${ }^{40}$. Nunca antes uma única espécie dominou a mudança na biosfera como os humanos o fazem hoje, e nunca antes o futuro próximo dependeu, como hoje, de decisões, insights e caprichos de uma única espécie. Considerar a estranheza da sociedade moderna é vital se pretendemos compreendê-la o suficiente para lidar com as consequências globais que provocará no futuro próximo. Entender o quão estranho o mundo de hoje é talvez nos confira uma consideração renovada acerca dos insights e do entendimento que tiveram nossos ancestrais, que mantiveram por muitos milênios uma relação muito mais estável com a biosfera do que demonstram as sociedades modernas.

Grande história é a primeira narrativa de origens para todos os humanos. Se a grande história é uma narrativa de origens, ela é também a primeira narrativa desse tipo para a humanidade como um todo. Surgindo, como o fez, em um mundo densamente interconectado, é a primeira construída por, e disponível a todos os seres humanos. Enquanto as narrativas tradicionais tentaram sumarizar o conhecimento de comunidades ou regiões particulares, ou de tradições culturais, essa é a primeira que tenta sintetizar conhecimento acumulado de todas as partes do mundo. Isso por si só sugere a riqueza de informação e a espantosa riqueza de detalhes de uma moderna narrativa de origens.

Narrativas de origem tradicionais proveram uma visão unificada para comunidades particulares, enfatizando as ideias que diferentes povos compartilharam, tal como as modernas histórias nacionais o fazem, promovendo uma visão unificada para os estados nacionais a despeito de diferenças internas em língua, cultura, religião e etnicidade. De maneira análoga, a grande história pode começar a gerar uma visão unificada para a humanidade como 
um todo, a despeito das muitas diferenças entre regiões, nações e tradições culturais. A construção e a disseminação de uma narrativa de origens global podem ajudar a gerar o senso de unidade humana que será preciso na medida em que as sociedades humanas navegarem coletivamente através dos desafios globais das próximas décadas. Ainda que os tribalismos culturais e nacionais que dominaram o mundo em que viveu Carr ainda estejam bem presentes hoje, ele ficaria surpreso em ver, surgindo pari passu, uma narrativa de origens para a humanidade como um todo.

Tão interconectado é o mundo de hoje que a ideia de uma humanidade unificada, com uma história própria, tem a relevância que faltava no tempo de Carr, quando as mais significativas comunidades humanas pareciam ser os estados-nação ou as regiões culturalmente coesas como o "Ocidente" ou o mundo islâmico, ou zonas dominadas por grandes impérios tradicionais como a China ou a Índia. Hoje, um sentido de cidadania global, de pertencimento à comunidade global da humanidade, não é apenas uma questão de precisão científica (falando em termos genéricos somos, afinal de contas, uma espécie notavelmente homogênea, tanto que a categoria, Homo sapiens tem uma precisão científica de que carece a categoria "ser humano chinês" ou "ser humano norte-americano"). Consciência acerca daquilo que todos os humanos compartilham é crescentemente uma questão de autopreservação, particularmente num mundo com armas nucleares. E. H. Carr escreveu O que é História? um ano antes da crise dos mísseis em Cuba, quando, de acordo com o presidente Kennedy, as chances de uma guerra total nuclear eram de "uma em três."

A tentativa de H. G. Wells de escrever uma história universal em 1919, quando os horrores da Grande Guerra ainda estavam vívidos em sua mente, foi motivada por um sentido similar de unidade humana. A paz, argumentou ele, necessitava de novas maneiras de pensar. Ela requeria:

...ideias históricas comuns. Sem tais ideias para mantê-los em cooperação harmônica, com nada além de tradições nacionalistas estreitas, egoístas e conflitantes, raças e povos estão destinados a vagar em direção ao conflito e à destruição. Essa verdade, que era aparente ao grande filósofo Kant um século ou mais atrás...é agora clara ao homem comum. ${ }^{42}$

Mais recentemente, o grande historiador mundial norte-americano William McNeill, defendeu com igual eloquência:

A humanidade inteira possui uma comunalidade a qual historiadores podem desejar entender tão firmemente quanto possam compreender o que vem a unir quaisquer grupos de menor porte. Em vez de amplificar conflitos, como uma historiografia paroquial inevitavelmente o faz, deve-se esperar de uma história mundial inteligível que diminua a letalidade dos encontros entre grupos por meio de cultivar um sentido de identificação individual com os triunfos e tribulações da humanidade como um todo. Isso, em verdade, me parece ser o dever moral da profissão historiográfica em nosso tempo. Precisamos desenvolver uma história ecumênica, plena de espaço para a diversidade humana em toda a sua complexidade. ${ }^{43}$

Como Wells entendeu, uma história universal é o veículo natural para uma história unificada da humanidade porque, diferentemente de histórias nacionais, a grande história primeiro encontra os humanos não como tribos belicosas, mas como uma espécie notoriamente homogênea. E essa é uma narrativa que pode ser contada agora com crescente precisão e confiança, e pode ajudar-nos a entender o lugar de nossa espécie não apenas no passado recente, mas na história da biosfera, e do Universo inteiro. 


\section{Notas finais}

1 Jean Bodin, século XVI, citado por Craig Benjamin "Beginnings and Endings", in Marnie HughesWarrington,

ed., Palgrave Advances in World Histories (Nova Iorque: Palgrave Macmillan, 2005), p. 95.

2 E.O. Wilson, Consilience: The Unity of Knowledge (Londres: Abacus, 1998).

3 E. H. Carr, What is History? (Harmondsworth: Penguin, 1964), primeira edição de 1961, apresentado em 1961 na forma de palestra em honra de George Macaulay Trevelyan, em Cambridge.

4 Carr, What is History? p. 150.

5 Sobre Humboldt como um historiador à frente de seu tempo, ver Fred Spier, Big History and the Future of Humanity, 2nd ed., Malden, Mass.: Wiley Blackwell, 2015, pp. 18-21, e Andrea Wulf, The Invention of Nature: The Adventures of Alexander von Humboldt, the Lost Hero of Science, (London: John Murray, 2015).

6 A distinção entre disciplinas paradigmáticas e préparadigmáticas foi introduzida por um livro cuja primeira edição aparece em 1962, um ano apenas após o livro de Carr: Thomas Kuhn, The Structure of Scientific Revolutions, 2nd ed. (Chicago: University of Chicago Press, 1970).

7 Carr, What is History? p. 7-8.

8 C. P. Snow, The Two Cultures and the Scientific Revolution (Cambridge, Cambridge University Press, 1959).

9 Carr, What is History? p. 32.

10 Carr, What is History? p. 26.

11 Carr, What is History? p. 84.

12 Carr, What is History? p. 23.

13 Carr, What is History? p. 24.
14 A obra de Collingwood, como a de Carr, foi subsídio elementar para estudantes de minha geração. Seu mais importante trabalho é R. G. Collingwood, The Idea of History, rev. ed. Jan Van der Dussen (Oxford and New York: Oxford University Press, 1994).

15 Citado de Robert C. Tucker, ed., The Marx-Engels Reader, 2nd ed. (New York and London: W.W. Norton \& Co., 1978), p. 595.

16 Carr, What is History? p. 30.

17 David Cannadine, ed., What is History Now? (Basingstoke: Palgrave/Macmillan, 2002).

18 Jean-François Lyotard, The Postmodern Condition: A Report on Knowledge, transl. Geoff Bennington and Brian Massumi (Minneapolis: University of Minnesota Press, 1984).

19 Um interessante exemplo é The History Manifesto de Jo Guldi and David Armitage, (Cambridge: CUP, 2014), que traz uma crítica agressiva à ênfase no curto prazo da historiografia contemporânea.

20 Uma relação inicial deve incluir Eric Chaisson, Cosmic Evolution: The Rise of Complexity in Nature (Cambridge, MA: Harvard University Press, 2001); David Christian, Maps of Time: An Introduction to Big History (Berkeley, CA: University of California Press, 2nd ed., 2011); Fred Spier, Big History and the Future of Humanity, (2nd ed., Malden, MA: Wiley/Blackwell, 2015); Cynthia Stokes Brown, Big History: From the Big Bang to the Present, (2nd ed., New York: New Press, 2012); um texto universitário, David Christian, Cynthia Stokes Brown, and Craig Benjamin, Big History: Between Nothing and Everything (New York: McGraw-Hill, 2014); antologias de ensaios, como Barry Rodrigue, Leonid Grinin and Andrey Korotayev, eds., From Big Bang to Galactic Civilizations: A Big History Anthology, Vol. 1, Our Place in the Universe (Delhi: Primus Books, 2015); e a publicação lindamente ilustrada Macquarie University Big 
History Institute, Big History (London: DK books, 2016).

21 Cannadine, ed., What is History Now? p. 149.

22 Essa sessão sintetiza e expande argumentos que apresentei em "The Return of Universal History". History

and Theory, Theme Issue, 49 (December, 2010), p. 5-26.

23 Erwin Schrödinger, What is Life? (Cambridge: CUP, 2000), p. 1 [publicado originalmente em 1944]; Schrödinger também estava bem atento às barreiras que a especialização impunha a essas ambições.

24 Carr, What is History? p. 57.

25 A série Cosmos, de Carl Sagan, foi televisionada pela primeira vez em 1980. A obra Cosmos, Earth, and Man: A Short History of the Universe (New Haven: Yale University Press, 1978) de Preston Cloud, foi publicada apenas dois anos antes, em 1978.

26 Há um bom relato sobre as metodologias reais na ciência moderna - em oposição às idealizadas - em John Ziman, Real Science: What it is, and what it means. (Cambridge: CUP, 2000).

27 Ver David Christian, "Historia, complejidad y revolución cronométrica" ["History, Complexity and the Chronometric Revolution"], Revista de Occidente, Abril 2008, No 323, 27-57, e David Christian, "History and Science after the Chronometric Revolution", in Steven J. Dick and Mark L. Lupisella, eds., Cosmos \& Culture: Cultural Evolution in a Cosmic Context, (NASA, 2009), pp. 441-462.

28 H.G. Wells, Outline of History: Being a Plain History of Life and Mankind, 3rd ed., (New York: Macmillan),1921, p. 1102.

29 John Mulvaney \& Johan Kamminga, Prehistory of
Australia (Sydney: Allen \& Unwin, 1999), p. 1-2.

30 Colin Renfrew, Prehistory: The Making of the Human Mind (London: Weidenfeld and Nicolson, 2007), p.41.

31 Cannadine, What is History Now? p. 153.

32 William H. McNeill, "History and the Scientific Worldview," History and Theory, 37, no. 1 (1998): p. 12-13.

33 Origins (Bulletin of the International Big History Association), 2016, VI.08, p. 7.

34 Andrew Wulf, The Invention of Nature: The Adventures of Alexander von Humboldt, the lost Hero of Science, London: John Murray, 2015. Capítulo 18, "Humboldt's Cosmos".

35 Podemos traduzir Goldilocks condition como "Condição Cachinhos Dourados", em analogia à estória infantil "Cachinhos de Ouro e os três ursos". Em resumo, refere-se a um ponto de interseção especial entre variáveis independentes, que funciona como condição sine qua non para colocar em marcha determinado processo macrohistórico (Nota do Tradutor).

36 Peter Hoffmann, Life's Ratchet How Molecular Machines Extract Order from Chaos (New York: Basic Books, 2012), é uma maravilhosa exploração acerca de como máquinas moleculares se utilizam da "tempestade molecular" criada pela energia aleatória em uma molécula individual de modo a impulsionar a química das células; e por que motivo, ao fazê-lo, não vem a violar a segunda lei da termodinâmica dado que depende de fontes adicionais de energia livre, em maior parte supridas pela molécula "bateria", a ATP.

37 Sobre a ideia de Noosfera, ver David Christian, "The Noösphere," em Edge.org Annual Question for 2017 (Jan 2017), https:/www.edge.org/ response-detail/27068. 
38 Marshall Berman, All that is Solid Melts into Air: the Experience of Modernity, (New York: Penguin, 1988, primeira edição de 1982), p. 15.

39 Para mais sobre essas questões, ver David Christian, "History and Time", Australian Journal of Politics and History, Volume 57, Number 3, 2011, pp. 353365, e John McNeill, Something New under the Sun: An Environmental History of the TwentiethCentury World (New York: W. W. Norton, 2000).

40 Mark Williams, Jan Zalasiewicz, et. al., "The Anthropocene Biosphere", The Anthropocene Review, (2015): p. 1-24.

41 Graham Allison and Philip Zelikow. Essence of Decision: Explaining the Cuban Missile Crisis, 2nd ed. (New York: Longman, 1999), p. 271.

42 Wells, H.G. Outline of History, 3rd ed., 1921, vi.

43 William H. McNeill, "Mythistory, or Truth, Myth, History, and Historians", The American Historical Review, Vol. 91, No. 1, (Feb., 1986), p. 7. 